\title{
Some Applications Of Nonlinear Regression Models In Forestry Research
}

\author{
by
}

Bijan Payandeh 1

\section{Abstract}

Many biological processes are basically nonlinear in nature and should be described as such in empirical modelling. Advantages of nonlinear regression models over their linear counterparts are discussed briefly. Examples of several nonlinear regression models useful in forestry are given and demonstrated graphically. With the ever-increasing availability of nonlinear regression rountines, it is hoped that more foresters will use such models in their research work and data analysis.

\section{Résumé}

Beaucoup de processus biologiques sont fondamentalement non linéaires et devraient donc être considérés comme tels dans les modèles empiriques. On discute brièvement des avantages des modèles de régression non linéaire par rapport aux modèles de régression linéaire. On donne plusieurs exemples de ces modèles utilisés en foresterie et on en fait la démonstration graphique. Étant donné la multiplication des sous-programmes utilisant la régression non linéaire, il est à espérer qu'un plus grand nombre de forestiers les utiliseront pour leurs travaux de recherche et l'analyse des données.

\section{Introduction}

By definition, a linear regression model is one that is linear in its parameters or coefficients. For example,

$Y=\beta_{0}+\beta_{1} X_{1}+\beta_{2} X_{2}+\beta_{3} X_{1}^{2}+\beta_{4} X_{2}^{2}+\ldots \epsilon$

is a multiple linear regression model.

Linear models have been used routinely for data analysis and empirical modelling in forestry and related fields. Most forestry researchers are familiar with the theory and assumptions of linear parameter estimation procedures. Extensive application of linear models stems from well developed methodology to satisfy linear regression assumptions such as: normality, linearity, and homogeneity of variance and convenience, i.e., availability of computer programs for linear regression. Also until recently, the only feasible method for fitting some nonlinear models was via logarithmic transformation.

Many biological systems exhibit behavior which is best described by nonlinear regression models. These are models which are nonlinear in their coefficients, such as

$$
\begin{aligned}
& Y=\beta_{1} X^{\beta 2} \times \epsilon \\
& \text { and } Y=\beta_{1} \mathrm{e}^{\left(-\beta_{2} / X+\beta_{3}\right)}+\epsilon
\end{aligned}
$$

\footnotetext{
'Department of the Environment, Canadian Forestry Service, Great Lakes
} Forest Research Centre, Sault Ste. Marie, Ontario P6A 5M7
The task of nonlinear parameter estimation is much more difficult than that of linear parameter estimation. In some cases it is possible to linearize the nonlinear models through the use of logarithmic or other transformations. This is true in the case of model (2) above. Even in these cases the use of transformed models presents a new set of difficulties. For example, logarithmic transformations have several inherent drawbacks, including the assumption of multiplicative error term in the original model and difficulties in evaluating the usual measures of goodness of fit such as $\mathrm{R}^{2}$, standard errors of the estimate (SEE) and significance in terms of the original data. In addition, transformed models usually result in biased estimates and are less precise than their nonlinear counterparts in terms of the untransformed data (Payandeh 1981).

Many otherwise useful, nonlinear models (Grossenbaugh 1965; Moser and Beers 1969; Yang et al. 1978; Ek et al. 1981) cannot be linearized. Such models are said to be "intrinsically nonlinear" and their parameters must be estimated by means of complex methods of successive approximation (c.f. Draper and Smith 1966; Weisberg 1980). Model (3) above is an example of an intrinsically nonlinear model. Fortunately, advances in nonlinear estimation procedures (Goldfeld and Ouandt 1972; Kennedy and Gentle 1980) and the development of widely available computer software have made nonlinear regression analysis readily available to forestry researchers.

The purpose of this paper is to discuss and illustrate several nonlinear models with forestry applications. It is hoped that it will serve as an introduction to readers unfamiliar with such models and encourage those who have been hesitant to use 
them because of the apparent complexity of the nonlinear parameter estimation procedures.

\section{Examples of Nonlinear Regression Models}

There are many nonlinear regression models which can be used in forestry research in general and in empirical modelling in particular. Examples of such models are: a) simple power (or allometric) function to express tree volume or weight as a function of diameter and/or height; b) exponential decay function to express stand density or mortality as a function of stand age; and c) sigmoidal growth function to express stand diameter, height, basal area or volume as a function of stand age and site index.

If properly chosen, nonlinear models usually fit most biological growth data as well as or better than the more complex linear models. Furthermore, nonlinear models often exhibit biologically plausible behavior when they are extrapolated. For example, the Richards (1959) growth function given below, with only three parameters, will fit many biological growth processes which have a sigmoidal pattern over time (see Grosenbaugh 1965 for other sigmoidal functions):

$\mathrm{Y}=\beta_{1}\left(1-\mathrm{e}^{-\beta_{2} \mathrm{X}}\right)^{\beta_{3}}+\epsilon$

where:

$Y=$ some quantity subject to change over time, e.g. basal area/ha

$\mathrm{X}=$ time or age

$\mathrm{e}=$ base of natural logarithms

$\beta s=$ parameters of the model to be estimated

$\epsilon=$ error term of the model.

In contrast, to obtain a satisfactory approximation to typical growth data by polynomial models, the degree of the polynomial, and hence the number of parameters to be estimated, is usually more than three. Almost any type of data can be numerically fitted to a satisfactory level of approximation by a polynomial. Such a polynomial may be of high order and, though seemingly mathematically satisfactory, the resulting function may be made up of several maxima, minima and inflection points within the scope of data set.

To illustrate the above advantages of nonlinear models over their linear counterparts, data from Plonski's (1974) yield tables were used. Tabular data for average stand diameter, density and basal area/ha for black spruce (Picea mariana [Mill.] B.S.P.) of site class I, and for stand ages between 20 and 100 years, were fitted to both linear and nonlinear models. The remaining data for stand ages between 110 and 150 years were used to examine the relative behavior of each model upon extrapolation. Table 1 summarizes the resulting regression equations.

Figure 1 and Table 1 indicate that in the case of stand DBH, the Richards growth function produced a slightly better fit than a second-degree polynomial for the range of data used, and that it produced estimates much closer to actual data upon extrapolation. Figure 2 and Table 1 clearly indicate the superiority of the simple exponential decay function over a third-degree polynomial for expressing stand density as a function of stand age. Although the polynomial model produced a slightly better fit than the exponential decay model within the data range, it virtually explodes upon extrapolation, resulting in negative density for stands 140 years and older. Similarly, Figure 3 indicates that, in the case of basal area, the Richards growth function is definitely superior to a third-degree polynomial. The polynomial model not only behaves very poorly upon extrapolation, but also results in negative estimates for stands 17 years and younger. These examples should clearly indicate the superiority of simple nonlinear models over the more complex and inflexible polynomial models.

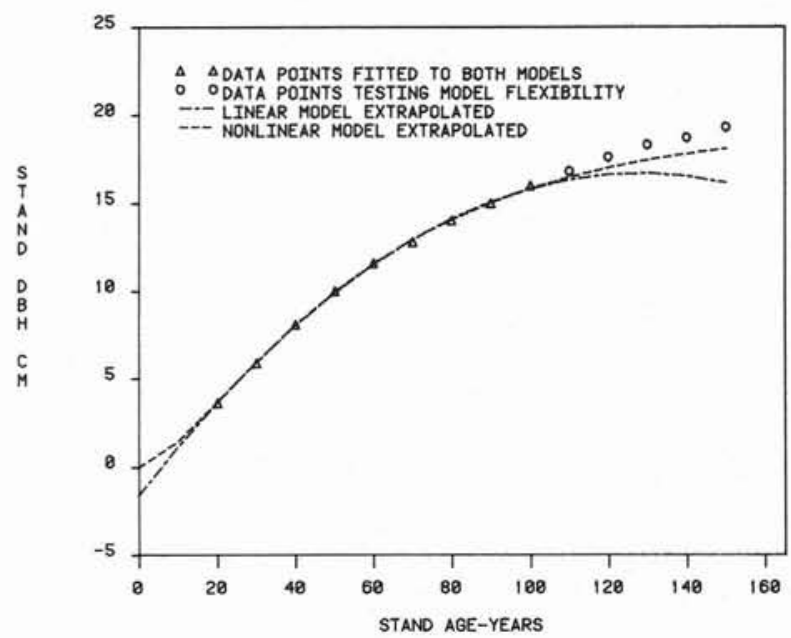

Figure 1. Comparison of linear and nonlinear models fitted to black spruce stand dbh - Plonski's site class I.

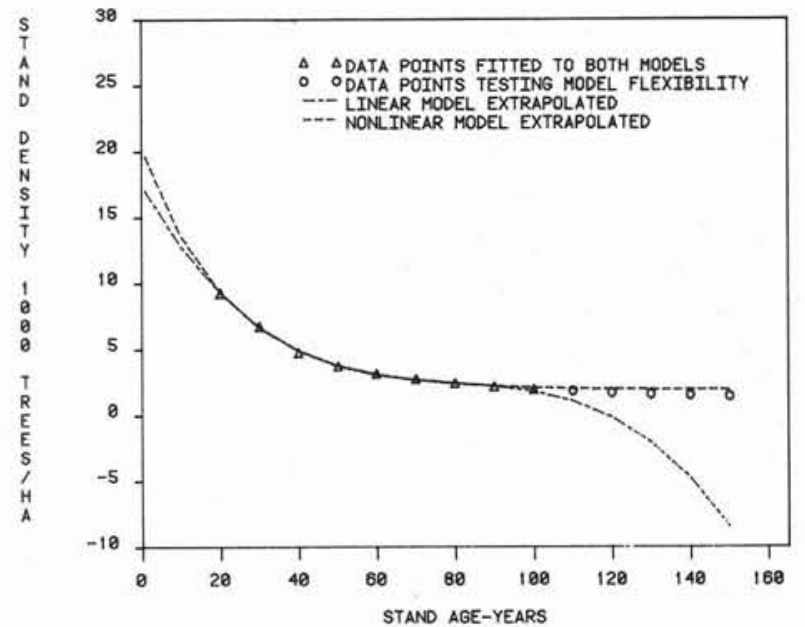

Figure 2. Comparison of linear and nonlinear models fitted to black spruce stand density - Plonski's site class I.

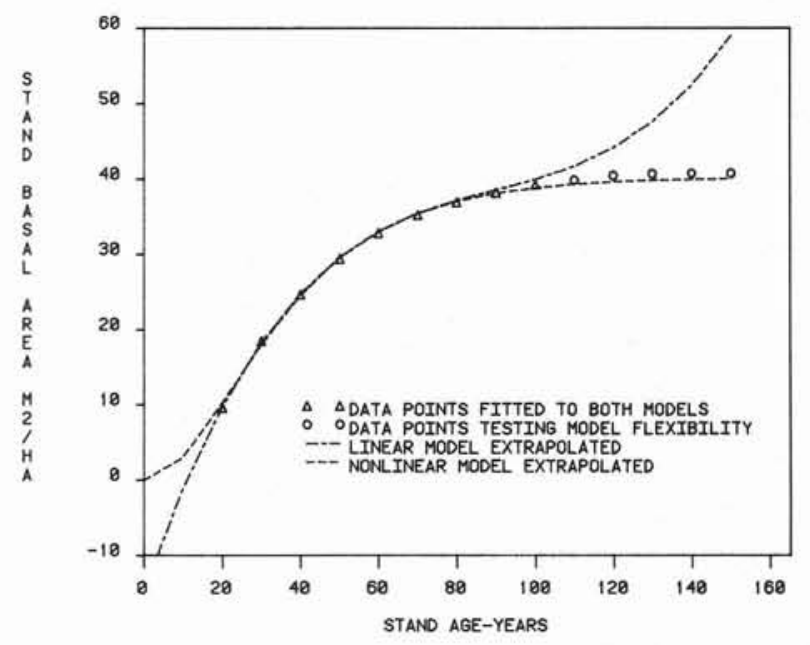

Figure 3. Comparison of linear and nonlinear models fitted to black spruce stand basal area - Plonski's site class I. 
Table 1. Linear and nonlinear regression models expressing average stand diameter, density and basal area/ha as a function of stand age for black spruce site class 1 from Plonski's yield tables.

\begin{tabular}{llrr}
\hline Stand variable & Regression equation & SEE & R $^{2}$ \\
\hline Avg. diam $(\mathrm{cm})$ & $\mathrm{DBH}=1.59+.286 \mathrm{~A}-.00112 \mathrm{~A}^{2}$ & .12 & .99 \\
& $\mathrm{DBH}=19.34\left(1-\mathrm{e}^{-.021 \mathrm{~A}}\right)^{1.554}$ & .99 & .10 \\
No. of trees/ha & $\mathrm{N}=17505-530.2 \mathrm{~A}+6.43 \mathrm{~A}^{2}-.027 \mathrm{~A}^{3}$ & 82.6 & .99 \\
& $\mathrm{~N}=1876+18562.3 \mathrm{e}^{-04563 \mathrm{~A}}$ & 89.2 & .99 \\
Basal area/ha $\left(\mathrm{m}^{2}\right)$ & $\mathrm{BA}=14.84+1.515 \mathrm{~A}-.0154 \mathrm{~A}^{2}+.000057 \mathrm{~A}^{3}$ & .12 & .99 \\
& $\mathrm{BA}=40.18\left(1-\mathrm{e}^{-.043 \mathrm{~A}}\right)^{2.465}$ & .99 \\
\hline
\end{tabular}

In addition, parameters of some nonlinear growth functions are amenable to theoretical interpretation. For example, in the case of the Richards growth function, $\beta_{1}$ is the upper asymptote, i.e. the maximum value attainable by the growth process, $\beta_{2}$ is a rate parameter, e.g., the rate of growth/unit of time, and $\beta_{3}$ is a rate and shape parameter. Figures 4-6 illustrate a variety of shapes and forms of the sigmoidal growth function produced by varying each of its three parameters. Figure 4 is an example of the so-called anamorphic growth functions produced by varying the value of $\beta_{1}$ or the upper asymptote parameter while holding the rate $\beta_{2}$ and the rate and shape $\beta_{3}$ parameters constant. Figure 5 demonstrates the effect of varying the rate $\beta_{2}$ parameter on the form and shape of the growth function, while Figure 6 shows the effect of changing the rate and shape $\beta_{3}$ parameter while holding the other two parameters constant. Varying either the rate $\beta_{2}$ or rate and shape $\beta_{3}$ parameters produces the so-called polymorphic growth patterns. It should be obvious, therefore, that the Richards growth function with only three parameters is highly flexible and capable of describing sigmoidal growth patterns of just about any shape and form.

Although each biological growth process is distinct, the biological growth model is often sufficient to characterize a wide range of such processes under normal conditions, i.e., when environmental factors such as nutrient, moisture, temperature, etc., are either stable or vary only slightly. If an environmental factor is varied within a range with no threshold effects, the anamorphic form of the Richards function (Lundgren and Dolid 1970; Piennar and Turnbull 1973) given below (Fig. 4) will provide a suitable model to express such a process:

$Y=\beta_{1} X_{1}\left(1-e^{-\beta_{2} X_{2}} \beta_{3}\right.$

where: $X_{1}=$ an environmental factor such as nutrient, moisture, temperature, light, etc.

$\mathrm{X}_{2}=$ time; other variables as defined earlier.

Payandeh (1974) employed an extension of the above model (6) in formulating site index curves for major timber species in Canada exhibiting polymorphic growth patterns (Fig. 7):

$\mathrm{Y}=\beta_{1} \mathrm{X}_{1} \beta_{2}\left(1-\mathrm{e}^{\left.-\beta_{3} \mathrm{X}_{2}\right)} \beta_{4} \mathrm{X}_{1} \beta_{5}\right.$

Most environmental factors, however, have much more complex effects on growth processes than can be adequately expressed by model (6). Nevertheless, an extension of the above model may be used to express reasonably well the growth processes affected by an environmental factor subject to thresholds:

$Y=\beta_{1} X_{1} \beta_{2} \beta_{3} X_{1}^{\beta_{4}}\left(1-e^{-\beta_{5}} X_{2}\right) \beta_{6} X_{1} \beta_{7}$

The effect of the term $\beta_{3} X_{1} \beta_{4}$ in conjunction with $X_{1} \beta_{2}$ is to allow for threshold effects of $X_{1}$, if any. The upper asymptote in the above model is a parabolic function of $X_{1}$, i.e., depending

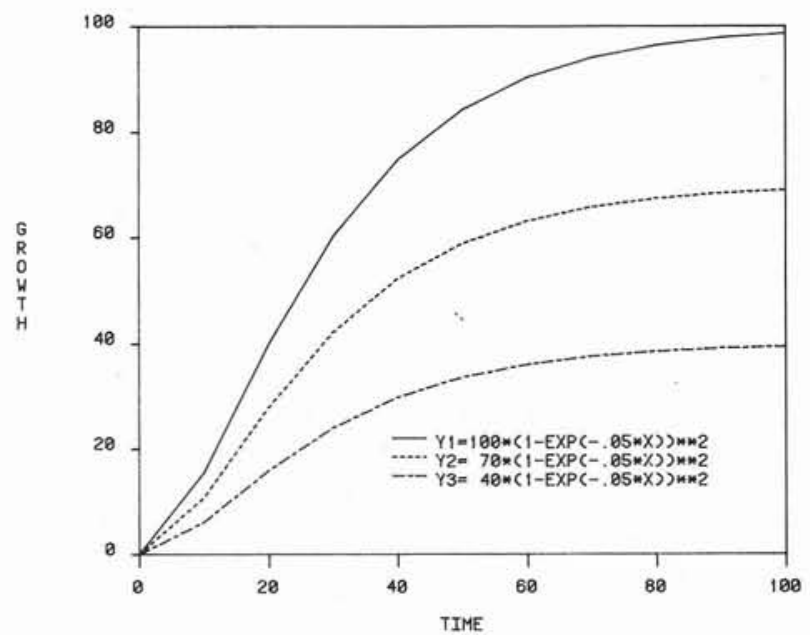

Figure 4. An example of sigmoidal growth function with varying upper asymptote parameter.

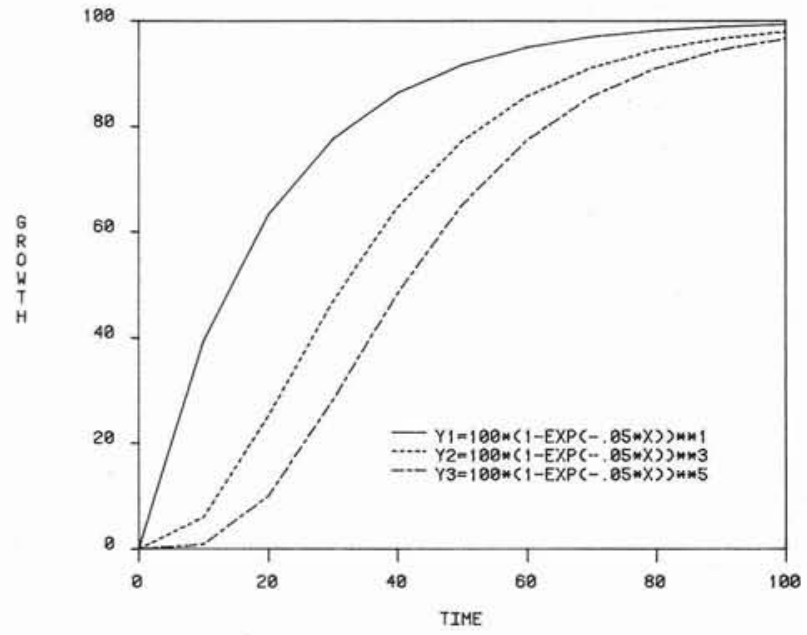

Figure 5. An example of sigmoidal growth function with varying rate parameter.

on the values of $X_{1}$ and $\beta \mathrm{s}$, the upper asymptote increases as $X_{1}$ increases up to a maximum, then it decreases rather sharply.

Payandeh et al. (1980) fitted the above model to two sets of spore germination data as a function of time and temperature. This model (Fig. 8) proved to describe the data better than the more complex mixed linear model used by Pearson et al. (1977) and that of the two-stage nonlinear-linear regression model used earlier by Payandeh et al. (1978). Recently, Payandeh and Haavisto (1982) employed the following exponential decay-exponential model to express seedfall 


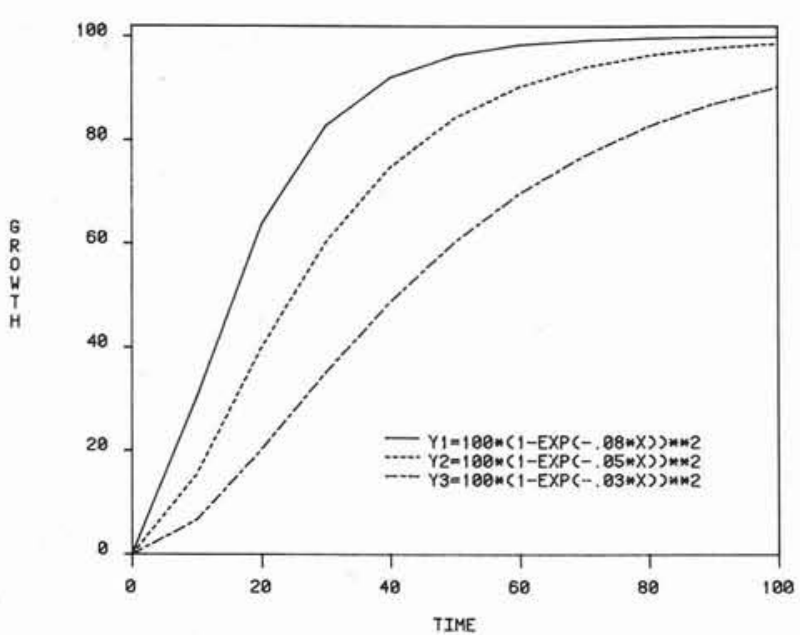

Figure 6. An example of sigmoidal growth function with varying rate and shape parameter.

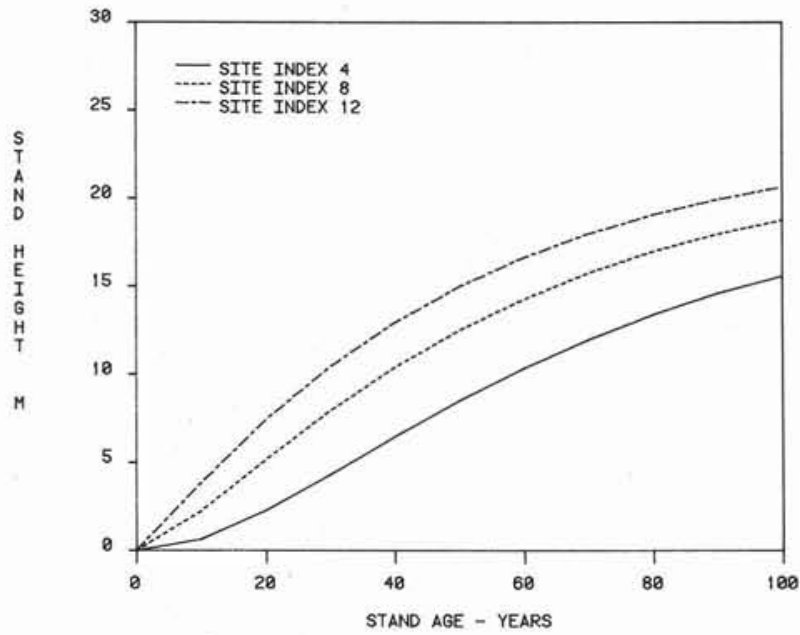

Figure 7. An example of polymorphic growth function for site index curves for peatland black spruce in Ontario.

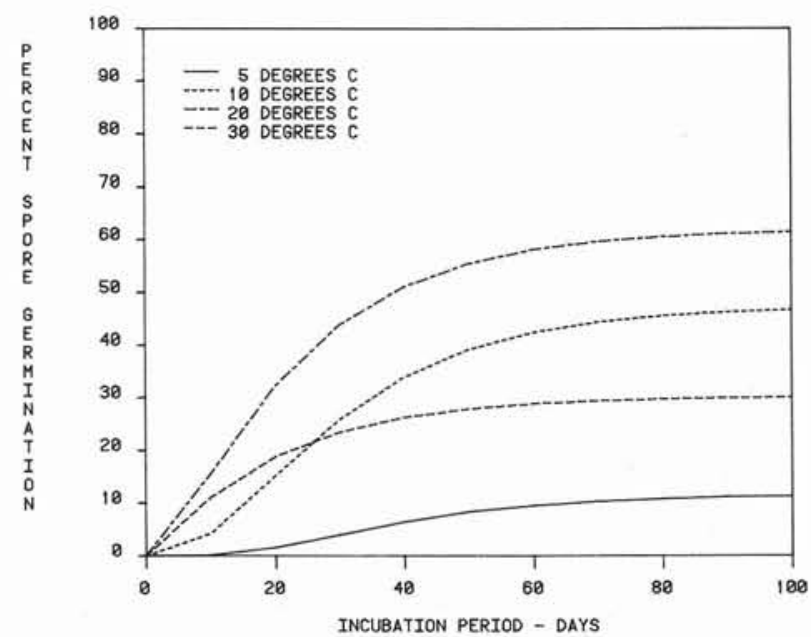

Figure 8. An example of polymorphic growth function subject to threshold effect (Payandeh et al. 1980). across a strip-cut as a function of strip-cut width and distance from the edge of the stand:

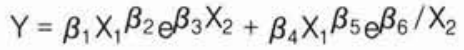

where: $Y=$ estimated seedfall/ha

$\mathrm{X}_{1}=$ strip-cut width in $\mathrm{m}$

$X_{2}=$ distance from the stand edges in $m$

$\beta \mathrm{s}=$ parameters of the model.

The above model fitted the two data sets very well and is suitable for describing a family of U-shaped relationships (Fig. 9).

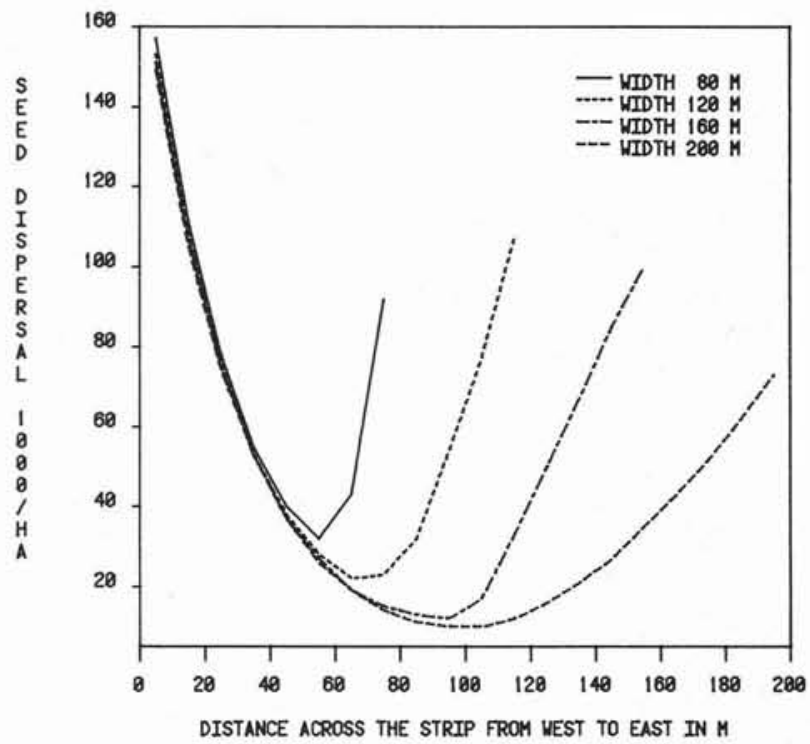

Figure 9. Black spruce stripcut annual seed dispersal as a function of strip width and distance from stand edge.

\section{Nonlinear Regression Analysis and Available Computer Programs}

Most of the models noted above cannot be linearized by transformation and thus require iterative procedures for parameter estimation. Basically in such procedures the initial parameter estimates of the model are changed until the mean residual error approaches least squares approximation. Several methods, e.g., Taylor series, steepest descent, Marquardt's compromise, etc. (Marquardt 1963; Draper and Smith 1966; Goldfeld and Quandt 1972), have been developed for this purpose. Some methods converge faster than others but may produce less accurate parameter estimates (Kennedy and Gentle 1980). Most routines, however, include several of these methods as options.

Nearly all educational and scientific computing centres, i.e., universities, colleges and research centres, etc., now have one or more nonlinear regression programs available in their scientific statistical software packages. Most of the commercial service bureaus such as IBM, Canada Systems Group, I.P. Sharp, Comshare, Computel, etc., also have one or more nonlinear regression routines available to their users. In addition, commercially available statistical software packages such as BMDP, SAS, SPSS, etc., provide similar routines. Several of the more recent nonlinear packages have as options both least squares and maximum likelihood parameter estimation procedures. With each procedure, the user has the option of inputting the model derivatives or letting them be approximated internally. Supplying analytical derivatives usually results in more efficient and more accurate parameter estimation. 
There are a few minor problems associated with some nonlinear models and their parameter estimation procedures and routines as noted below:

1) Each model usually has mathematical properties that affect how it describes a particular relationship. For example, the Johnson-Schumacher (Johnson 1935; Schumacher 1939; Grosenbaugh 1965) model always has an inflection point at 0.135 of the upper asymptote. Also, the Chapman-Richards (Chapman 1967; Pienaar and Turnbull 1973) model tends to develop early asymptotes just beyond the range of the data for limited data sets, i.e., extrapolation requires cautions.

2) In some cases logarithmic transformations may control heteroscedasticity, but weighting may be required for such problems in nonlinear regression.

3) Some nonlinear models might result in loss of additivity when applied to estimate volume or weight (biomass) components and total simultaneously. Kozak (1970) discussed this problem and suggested how to avoid it.

4) Because of the iterative nature of the parameter estimation procedures, they often do not result in a unique solution to parameter estimates.

5) If initial parameter estimates are too crude, the estimation procedures may not converge or the rate of convergence may be too slow, i.e., it may take a very large number of iterations to find a final solution.

Therefore, users unfamiliar with such routines are advised to consult with a professional biometrician to avoid costly computer runs and frustration, particularly when they are attempting to fit large sets of data to complex models and have only poor initial estimates of the parameters

\section{References}

Chapman, D.G. 1967. Statistical problems in population dynamics. $p$ 147-162 in Proc. Fifth Berkeley Symp. Math. Stat. and Probab. Univ. of Calif. Press, Berkeley and Los Angeles.

Draper, N.R. and H. Smith. 1966. Applied regression analysis. John Wiley and Sons Inc., New York, 407 p.

Ek, A.R., E.T. Birdsall and J. Spears. 1981. Total and merchantable tree height equations for lake states tree species. Coll. For. Univ., Minn., Staff Pap. No. 27, 15 p. plus append.

Goldfeld, S.M. and R.M. Quandt. 1972. Nonlinear methods in econometrics. North-Holland Publ. Co., London. 280 p.
Grosenbaugh, L.R. 1965. Generalization and reparametrization of some sigmoid and other nonlinear functions. Biometrics 21: 708-714.

Johnson, N.O. 1935. A trend line for growth series. J. Am. Stat. Assoc. 30: 717.

Kennedy, W.J. and J.E. Gentle. 1980. Statistical computing. Marcel Dekker, Inc, New York. 591 p

Kozak, A. 1970. Methods for ensuring additivity of biomass components by regression analysis. For. Chron. 45(5): 402-404.

Lundgren, A.L. and W.A. Dolid. 1970. Biological growth functions describing published site index curves for Lake States timber species. USDA For. Serv., North Central For. Exp. Stn. Res. Pap. NC-36. $9 \mathrm{p}$.

Marquardt, D. 1963. An algorithm for the least squares estimation of nonlinear models. J. Soc. Ind. Appl. Math. 2: 431-441.

Moser, J.W. and T.W. Beers. 1969. Parameter estimation in nonlinear volume equations. J. For. 67: 878-879

Payandeh, B. 1974. Nonlinear site index equations for several major Canadian timber species. For. Chron. 47(5): 194-196.

Payandeh, B. 1981. Choosing regression models for biomass prediction equations. For. Chron, 57(5): 229-232.

Payandeh, B., D.M. MacLeod and D.R. Wallace. 1978. Germination of Entomophthora aphidis resting spores under constant temperature. Can. J. Bot. 56(19): 2328-2333.

Payandeh, B., D.R. Wallace and D.M. MacLeod. 1980. An empirical regression function suitable for modelling spore germination subject to temperature threshold. Can. J. Bot. 58(8): 936-961

Payandeh, B. and V.F. Haavisto. 1982. Prediction equations for peatland black spruce seed production and dispersal in northern Ontario. For. Chron. 58(2): 96-99.

Pearson, R.C., H.S. Aldwinckle and R.C. Seem. 1977. Teliospore germination and basidiospore formation in Gymnosporangium juniperivirginianae: a regression model of temperature and time effects. Can. J. Bot. 55: 2382-2837.

Pienaar, L.V. and K.J. Turnbull. 1973. The Chapman-Richards - generalization of Van Bertalanffy's growth model for basal area growth and yield in even-aged stands. For. Sci. 19(1):2-22.

Plonski, W.L. 1974. Normal yield tables (metric) for major forest species of Ontario. Ont. Min. Nat. Resour., Div. For. 40 p.

Richards, F.J. 1959. A flexible growth function for empirical uses. J. Exp. Bot. 10(29): 290-300.

Schumacher, F.X.1939. A new growth curve and its relation to timber yield studies. J. For. 37: 819-820.

Weisberg, S. 1980. Applied linear regression. John Wiley and Sons, New York. 283 p.

Yang, R.C., A. Kozak and J.H.G. Smith. 1978. The potential of Weibull-type functions as flexible growth curves. Can. J. For. Res. 8: $421-431$

ECOlOgical Services
for Planning Limited
- Private Forest Land Management
- Urban Forestry
- Soil, Vegetation, and Resource Inventory
- Slope Stabilization and Erosion Control
- Specialists in Forest Soil Survey and Interpretations for
Management
530 willow Road - Unit 10-Gueiph, Ontario- $\mathrm{N} 1 \mathrm{H}$ 7G4 - Telephone 836 -6050

